Research Article

\title{
Development of Steel Fiber-Reinforced Expanded-Shale Lightweight Concrete with High Freeze-Thaw Resistance
}

\author{
Mingshuang Zhao, ${ }^{1,2}$ Xiaoyan Zhang, ${ }^{1,3}$ Wenhui Song, ${ }^{2,3}$ Changyong Li $\mathbb{D},{ }^{1,3}$ \\ and Shunbo Zhao $\mathbb{D}^{1,2}$ \\ ${ }^{1}$ International Joint Research Lab for Eco-Building Materials and Engineering of Henan, \\ North China University of Water Resources and Electric Power, Huayuan Campus, No. 36 Beihuan Road, \\ Zhengzhou 450045, China \\ ${ }^{2}$ Henan Province Collaborative Innovation Center for High-Efficient Utilization and Support Engineering of Water Resources, \\ North China University of Water Resources and Electric Power, Longzihu Campus, No. 136 Jinshui East Road, \\ Zhengzhou 450046, China \\ ${ }^{3}$ School of Civil Engineering and Communication, North China University of Water Resources and Electric Power, \\ Huayuan Campus, No. 36 Beihuan Road, Zhengzhou 450045, China
}

Correspondence should be addressed to Shunbo Zhao; sbzhao@ncwu.edu.cn

Received 11 January 2018; Revised 23 February 2018; Accepted 12 March 2018; Published 2 April 2018

Academic Editor: Antonio Gilson Barbosa de Lima

Copyright ( 2018 Mingshuang Zhao et al. This is an open access article distributed under the Creative Commons Attribution License, which permits unrestricted use, distribution, and reproduction in any medium, provided the original work is properly cited.

For the popularized structural application, steel fiber-reinforced expanded-shale lightweight concrete (SFRELC) with high freezethaw resistance was developed. The experimental study of this paper figured out the effects of air-entraining content, volume fraction of steel fibers, and fine aggregate type. Results showed that while the less change of mass loss rate was taken place for SFRELC after 300 freeze-thaw cycles, the relative dynamic modulus of elasticity and the relative flexural strength presented clear trends of freeze-thaw resistance of SFRELC. The compound effect of the air-entraining agent and the steel fibers was found to support the SFRELC with high freeze-thaw resistance, and the mechanisms were explored with the aid of the test results of water penetration of SFRELC. The beneficial effect was appeared from the replacement of lightweight sand with manufactured sand. Based on the test results, suggestions are given out for the optimal mix proportion of SFRELC to satisfy the durability requirement of freeze-thaw resistance.

\section{Introduction}

On the purpose of utilizing the local raw materials, steel fiberreinforced expanded-shale lightweight concrete (SFRELC) was developed, which applied the expanded shale as coarse aggregates and the lightweight sand of expanded-shale's byproduct or the manufactured sand as fine aggregates. Based on the systematically experimental studies, SFRELC has reliable basic mechanical properties [1-4], reasonable strength development [5], enhanced carbonization resistance, and reduced shrinkage $[5,6]$. To verify the possibility of applying SFRELC in the wet environments at cold and severe cold areas of China [7], the experimental study was carried out on the freeze-thaw resistance of SFRELC in this paper.
After searching the literature, although few investigations were found to research the freeze-thaw resistance of steel fiber-reinforced lightweight aggregate concrete (SFRLAC), the results exhibited a good prospect for the development of SFRELC with high freeze-thaw resistance. Ishida et al. [8] reported that the freeze-thaw resistance of SFRLAC could be improved by the increase in the bond force between slenderer steel fibers with a large bond area and a high-strength matrix. Huo et al. $[9,10]$ discovered that the freeze-thaw resistance of pumice lightweight concrete could be enhanced by adding hybrid fibers (steel fiber and polypropylene fiber) due to the decrease of strength loss, although the bond between steel fibers and the matrix became weaker with the increase of freeze-thaw cycles. Li et al. [11] concluded that steel fibers can 
TABle 1: Physical properties of lightweight sand and manufactured sand.

\begin{tabular}{lccccccc}
\hline Identifier & $\begin{array}{c}\text { Fineness } \\
\text { modulus }\end{array}$ & $\begin{array}{c}\text { Particle density } \\
\left(\mathrm{kg} / \mathrm{m}^{3}\right)\end{array}$ & $\begin{array}{c}\text { Bulk density } \\
\left(\mathrm{kg} / \mathrm{m}^{3}\right)\end{array}$ & $\begin{array}{c}1 \mathrm{~h} \text { water } \\
\text { absorption }(\%)\end{array}$ & $\begin{array}{c}\text { Mud content } \\
(\%)\end{array}$ & $\begin{array}{c}\text { Stone powder } \\
(\%)\end{array}$ & $\begin{array}{c}\text { Methylene blue value } \\
(\mathrm{g} / \mathrm{kg})\end{array}$ \\
\hline $\mathrm{L}$ & 3.56 & 1659 & 946 & 9.0 & 1.5 & - & 7.9 \\
$\mathrm{M}$ & 2.50 & 2730 & 1930 & 0.90 & - & 0.75 \\
\hline
\end{tabular}

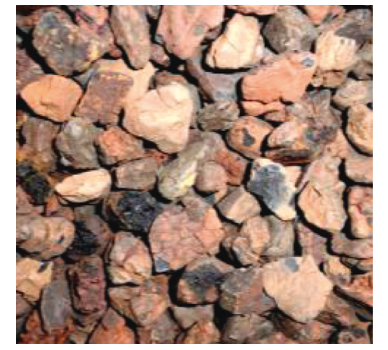

(a)

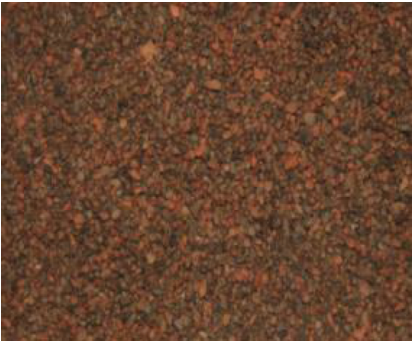

(b)

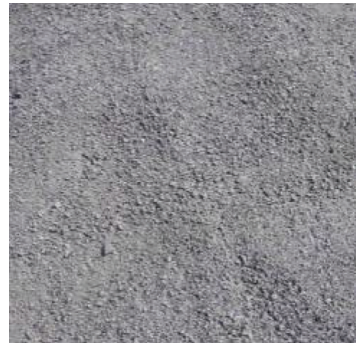

(c)

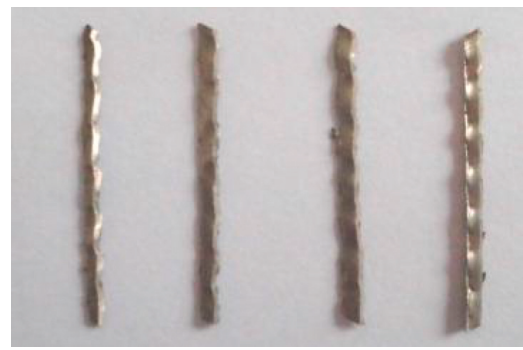

(d)

Figure 1: Morphology features of aggregates and steel fibers. (a) Expanded shale; (b) lightweight sand; (c) manufactured sand; (d) steel fibers.

improve the freeze-thaw resistance of SFRLAC characterized by the mass loss rate and the relative dynamic modulus of elasticity, as the matrix spalling from frost heaving was restrained by steel fibers.

In view of the benefit of air-entraining to freeze-thaw resistance of concrete [12-16], the content of the airentraining agent was also considered as a main factor in this paper. The freeze-thaw resistance of SFRELC was experimentally studied and comprehensively evaluated by the indexes of the mass loss rate, relative dynamic modulus of elasticity, and relative flexural strength. The compound effect of the air-entraining agent and steel fibers and the beneficial effect of manufactured sand on freeze-thaw resistance of SFRELC are analyzed. The mechanisms are explored with the aid of test results of water penetration of SFRELC. Suggestions are given out for the optimal mix design of SFRELC with high freeze-thaw resistance.

\section{Experiment}

2.1. Raw Materials. The ordinary silicate cement was grade 42.5 , the water requirement of normal consistency was $26.4 \%$, and the initial and final setting times were $150 \mathrm{~min}$ and $248 \mathrm{~min}$. The compressive strength was $22.8 \mathrm{MPa}$ at 3 days and $50.8 \mathrm{MPa}$ at 28 days, and the tensile strength was 4.1 $\mathrm{MPa}$ at 3 days and $8.0 \mathrm{MPa}$ at 28 days.
The sintering expanded shale with a maximum size of $20 \mathrm{~mm}$ was used as coarse aggregates sieved in continuous gradation based on the maximum density principle $[17,18]$. The bulk and particle densities were $800 \mathrm{~kg} / \mathrm{m}^{3}$ and $1274 \mathrm{~kg} / \mathrm{m}^{3}$, the cylinder compressive strength was $5.0 \mathrm{MPa}$, the 1 -hour water absorption was $6.1 \%$, and the mud content was $0.2 \%$.

Two kinds of fine aggregates were used, respectively. One was the lightweight sand made of the byproduct of sintering expanded shale in continuous gradation with a size of $1.6-5 \mathrm{~mm}[17,18]$ and another was the manufactured sand $[19,20]$. Table 1 lists their physical properties.

The steel fiber was of milling type with length $l_{\mathrm{f}}=30 \mathrm{~mm}$ and equivalent diameter $d_{\mathrm{f}}=0.8 \mathrm{~mm}$. The aspect ratio $l_{\mathrm{f}} / d_{\mathrm{f}}=37.5$.

Figure 1 shows the morphology features of coarse expanded shale, lightweight sand, manufactured sand, and steel fibers.

Others were tap water, polycarboxylic acid superplasticizer with $19 \%$ water-reducing rate, and polycarboxylic acid air-entraining admixture.

2.2. Mix Proportion of SFRELC. The mix proportion of SFRELC was designed in accordance with the specifications of Chinese standards $[17,21]$, where the absolute volume method was adopted. The volume fraction of steel fibers $\left(\rho_{\mathrm{f}}\right)$, 
TABLE 2: Mix proportion of concrete.

\begin{tabular}{|c|c|c|c|c|c|c|c|}
\hline Mix no. & $m_{\mathrm{ae}}(\% o)$ & $\rho_{\mathrm{f}}(\%)$ & Cement $\left(\mathrm{kg} / \mathrm{m}^{3}\right)$ & Water $\left(\mathrm{kg} / \mathrm{m}^{3}\right)$ & Steel fiber $\left(\mathrm{kg} / \mathrm{m}^{3}\right)$ & Sand $\left(\mathrm{kg} / \mathrm{m}^{3}\right)$ & Expanded shale $\left(\mathrm{kg} / \mathrm{m}^{3}\right)$ \\
\hline L0.00/0.0 & 0.00 & 0.0 & 460 & 138 & - & 490 & 520 \\
\hline L0.00/0.8 & 0.04 & 0.8 & 550 & 165 & 62.4 & 452 & 469 \\
\hline L0.04/0.8 & 0.04 & 0.8 & 550 & 165 & 62.4 & 452 & 469 \\
\hline L0.08/0.8 & 0.08 & 0.8 & 550 & 165 & 62.4 & 452 & 469 \\
\hline L0.12/0.8 & 0.12 & 0.8 & 550 & 165 & 62.4 & 452 & 469 \\
\hline L0.08/0.0 & 0.08 & 0.0 & 460 & 138 & - & 490 & 520 \\
\hline L0.08/0.4 & 0.08 & 0.4 & 505 & 153 & 31.2 & 471 & 494 \\
\hline L0.08/1.2 & 0.08 & 1.2 & 595 & 179 & 93.6 & 432 & 443 \\
\hline M0.08/0.8 & 0.08 & 0.8 & 550 & 165 & 62.4 & 743 & 469 \\
\hline
\end{tabular}

the content of the air-entraining agent $\left(m_{\mathrm{ae}}\right)$, and the type of fine aggregates were considered as the test parameters. Based on previous studies of fundamental properties of SFRELC with good workability [1-6], the water-cement ratio was fixed as $w / c=0.30$, while the sand ratio was $42 \%$ and the dosage of the water reducer was $4.0 \%$ cement mass. Table 2 lists their combinations for the test of 9 trials, where the letter in mix no. is the identifier of fine aggregates and the following digits represent $m_{\mathrm{ae}}$ and $\rho_{\mathrm{f}}$.

Based on previous experimental studies, prewetting the lightweight aggregates had beneficial effects on the mechanical properties especially on the shrinkage reduction of SFRELC [1-6]. This may also be beneficial to decrease the water penetration and to increase the freeze-thaw resistance of SFRELC. Zhao et al. [22] reported that the water penetration was reduced for SFRLAC with saturated lightweight aggregates, and Ali et al. [23] reported that the freeze-thaw resistance of lightweight aggregate concrete was improved at early ages by increasing the saturation level of aggregates. Although there were some contract conclusions [24, 25] or no relationship $[26,27]$ reported, the differences may be resulted from the different pores' structure (open or closed) and water absorption of lightweight aggregates [15, 28, 29]. Therefore, the expanded shale and lightweight sand of this experiment were prewetted as the saturated dry surface by using the additional water counted with the 1-hour water absorption. All mixes of this study had good workability with slump of $120 \mathrm{~mm}-150 \mathrm{~mm}$.

2.3. Preparation of Specimens. Specimens for the freeze-thaw test were $100 \mathrm{~mm} \times 100 \mathrm{~mm} \times 400 \mathrm{~mm}$ prisms; 189 specimens for 9 trials were prepared, and each trial had 21 specimens. Specimens for the water penetration test were circular truncated cones with a bottom diameter of $185 \mathrm{~mm}$, tip diameter of $175 \mathrm{~mm}$, and height of $150 \mathrm{~mm}$; 54 specimens for 9 trials were prepared, and each trial had 6 specimens.

The single horizontal shaft forced mixer was used. The expanded shale and lightweight sand (except for M0.08/0.8) were firstly prewetted in the mixer for 1 hour, and then, the manufactured sand (only for M0.08/0.8), the cement, and half dosage of the mix water were added and mixed for $30 \mathrm{~s}$. During the mixing, the water reducer and air-entraining agent as well as residual mix water were added. After that, the steel fiber was sprinkled into the mixer and mixed for $3 \mathrm{~min}$
The specimens formed by steel moulds on the vibration platform. After being cast for 24 hours, they moved from moulds and cured in the standard curing room for 28 days before testing.

2.4. Test Methods. Test methods of this experiment were in accordance with the specifications of the Chinese standard GB/T 50082 [30] and ASTM standard C666 [31]. The freezethaw resistance was measured by using the test method for rapid freezing and thawing in water, and the main test apparatuses were the rapid freeze-thaw test machine, the tester of the dynamic modulus of elasticity, the hydraulic universal test machine, and the balance. The freeze-thaw resistance was presented by the mass loss rate $\left(\Delta m_{n}\right)$ and the relative dynamic modulus of elasticity $\left(P_{n}\right)$ calculated as follows:

$$
\begin{aligned}
\Delta m_{n} & =\frac{m_{0}-m_{n}}{m_{0}} \times 100, \\
P_{n} & =\frac{f_{n}^{2}}{f_{0}^{2}} \times 100,
\end{aligned}
$$

where $m_{0}$ and $m_{n}$ are the mass of the specimen at the beginning and after $n$ cycles of the freeze-thaw test, respectively, and $f_{0}$ and $f_{n}$ are the transversal base frequency of the specimen at the beginning and after $n$ cycles of the freeze-thaw test, respectively.

The durability factor $(D F)$ was used to evaluate the freeze-thaw resistance [7]:

$$
D F=\frac{f_{300}^{2}}{f_{0}^{2}} \times 100,
$$

where $f_{300}$ is the transversal base frequency of the specimen after 300 cycles of the freeze-thaw test.

Before 300 cycles of freezing and thawing, if the relative dynamic modulus of elasticity $\left(P_{n}\right)$ and the mass loss rate $\left(\Delta m_{n}\right)$ reached $60 \%$ and $5 \%$, respectively, at $n$ cycles, then the $D F$ was computed as follows:

$$
D F=0.6 \times \frac{n}{300} .
$$

Based on previous studies [9-11], the strength loss of SFRLAC is better to reflect the freeze-thaw resistance. Therefore, the flexural strength of SFRELC was tested in accordance with the specification of the Chinese standard 


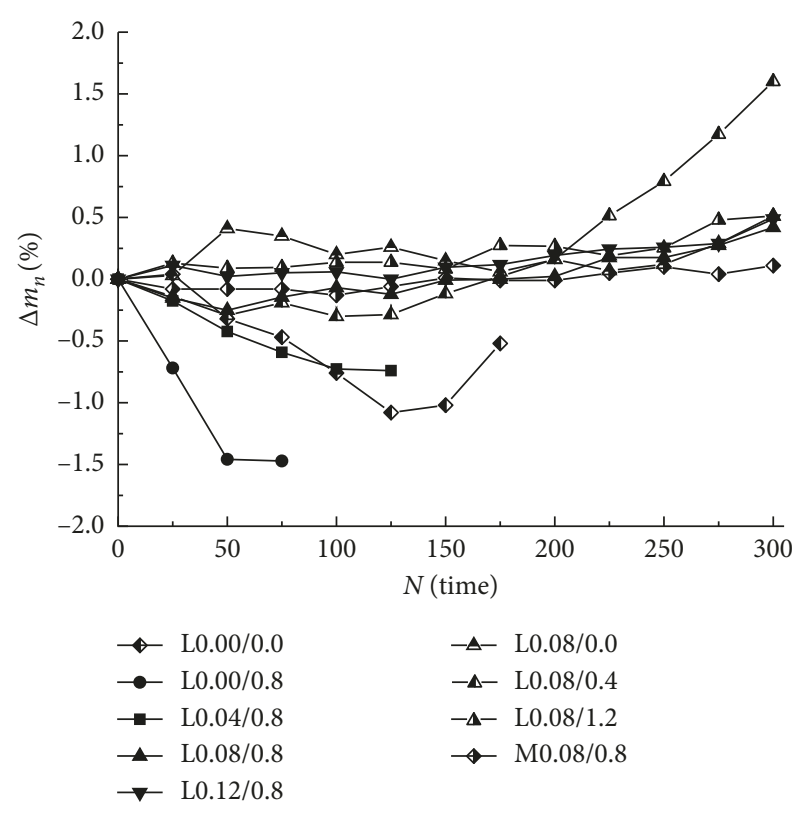

Figure 2: Changes of the mass loss rate with freezing-thawing cycles.

GB/T 50081 [32]. The concentrated loads were exerted on the three dividing points, and the relative flexural strength $\left(f_{r}\right)$ was defined as follows:

$$
f_{r}=\frac{f_{n}}{f_{0}} \times 100,
$$

where $f_{0}$ and $f_{n}$ are the flexural strength of the specimen at the beginning and after $n$ cycles of the freeze-thaw test, respectively.

To explain the freeze-thaw mechanism in aspect of the water transport property of SFRELC, the depth of water penetration was measured [30]. The main test apparatuses were the testing machine for water penetration of concrete, the hydraulic universal test machine, and the steel ruler. After the specimens in a group were fixed in the testing machine, the hydraulic pressure was exerted within $1.2 \pm$ $0.05 \mathrm{MPa}$ for 24 hours. Then, the specimens were split on the hydraulic universal test machine. The depth of the water stain was measured by the steel ruler at 10 points in equal space divided along the bottom splitting line. The depth of water penetration of each specimen was counted as the mean value of these 10 points and that of one group $\left(h_{\mathrm{p}}\right)$ was the mean value of six specimens.

\section{Results and Discussion}

3.1. Mass Loss Rate. The mass change of the SFRELC matrix comes mainly from two parts: one is the increment due to the water absorbed in the pores and capillaries of concrete during freezing and thawing and another is the decrement due to the surface peeling of set cement and aggregates. When the latter is greater than the former, the mass loss rate computed by formula (1) is positive, which always means the better internal structure the matrix has, and the freeze-thaw

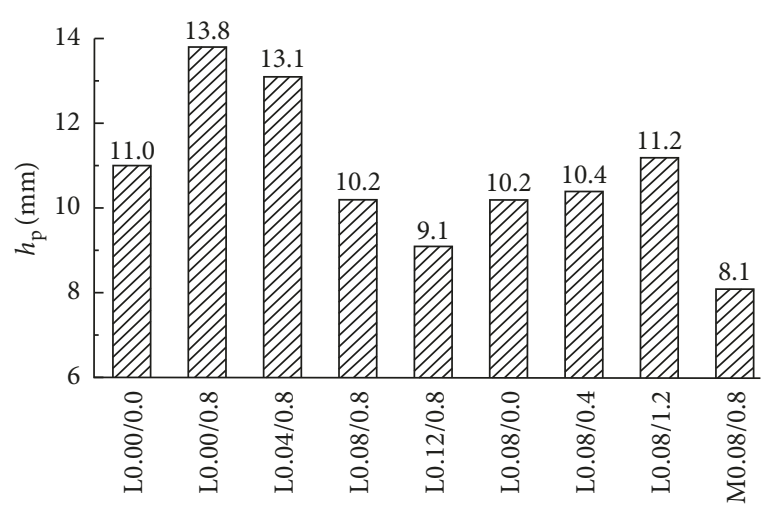

FIGURE 3: Test values of the height of water penetration.

damage takes place from the surface successively. When the latter is lower than the former, the mass loss rate is negative, which always means the poor internal structure the matrix has, and the freeze-thaw damage takes place because of the internal expansion of absorbed water inside the pores and capillaries [12, 33].

Figure 2 presents the changes of mass loss rate of SFRELC with the freeze-thaw cycles. The negative mass loss rate of L0.00/0.0 increased by adding steel fibers in L0.00/0.8. This condition was improved successively by the addition of the air-entraining agent from $0.4 \%$ to $1.2 \%$. When the content of the air-entraining agent was not less than $0.8 \%$, the mass loss rate of SFRELC became positive normally. Under the condition of SFRELC with $0.8 \%$ air-entraining agent, the mass loss rate changed from negative to positive with $\rho_{\mathrm{f}}=0.4 \%$ and $0.8 \%$ before 175 freeze-thaw cycles, and then, it remained positive and increased with the increasing freeze-thaw cycles. When $\rho_{\mathrm{f}}=1.2 \%$, the mass loss rate remained positive all the time. When $N=300$ and $\Delta m_{n}=0.42 \%$ and $0.51 \%$ for SFRELC with $\rho_{\mathrm{f}}=0.8 \%$ and $1.2 \%$, the mass loss rate was the same for L0.08/0.0 without steel fibers. Compared to L0.08/0.8 with lightweight sand, the mass loss rate of $\mathrm{M} 0.08 / 0.8$ with manufactured sand changed slightly until $N=300$.

The changes of mass loss rate were identical to the water penetration properties as shown in Figure 3. Compared to L0.00/0.0, L0.08/0.0 had a higher resistance to water penetration with $7.27 \%$ reduction of $h_{\mathrm{p}}$ and $\mathrm{L} 0.00 / 0.8 \mathrm{had}$ a lower resistance to water penetration with $25 \%$ increment of $h_{\mathrm{p}}$. This exhibited the different roles of the air-entraining agent and steel fibers affecting the microstructure of SFRELC. The air-entraining agent imported even dispersed bubbles with minuteness and closed and mutually uncorrelated characteristics [13-15], which led to the higher density of SFRELC matrix with improved uniformity of zigzag capillaries. The steel fibers increased the connectivity of internal pores and capillaries due to the defects of interfaces along steel fibers in the matrix $[9,10,22]$. Therefore, the results of water penetration of SFRELC reflected the compound function of the air-entraining agent and steel fibers.

With the increase of $m_{\mathrm{ae}}=0.04 \%{ }_{0}-0.12 \% \mathrm{o}, h_{\mathrm{p}}$ of SFRELC dropped down obviously. Compared to L0.04/0.8, $h_{\mathrm{p}}$ of 


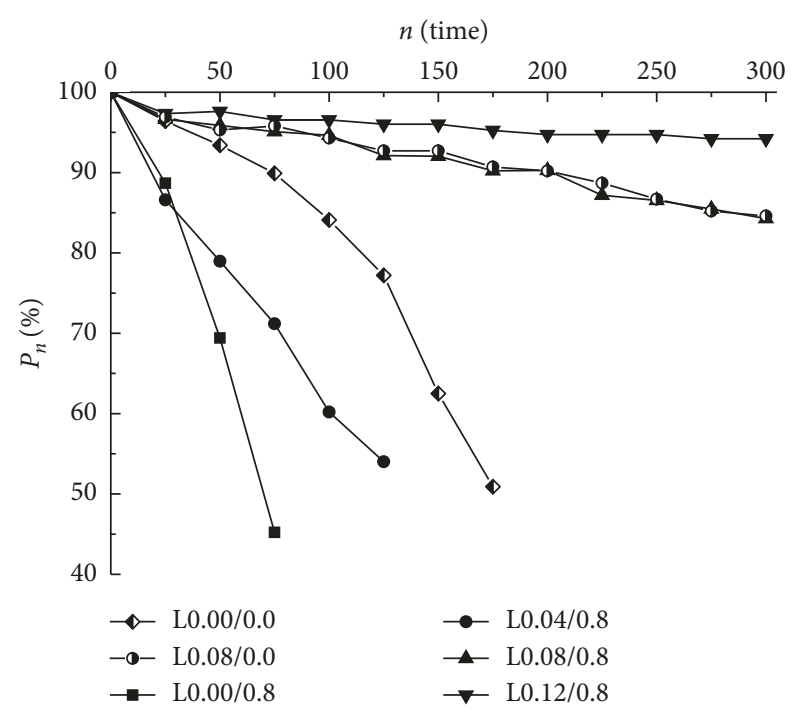

FIGURE 4: Changes of the relative dynamic modulus of elasticity affected by content of the air-entraining agent.

L0.08/0.8 and L0.12/0.8 reduced $22.1 \%$ and $30.5 \%$, respectively. This reflects the marked benefit of air-entraining to improve the resistance of SFRELC to water penetration. When $m_{\mathrm{ae}}=0.08 \%$, $h_{\mathrm{p}}$ of SFRELC with lightweight sand was almost equal except the larger one, $11.2 \mathrm{~mm}$ of L0.08/1.2. Combined with $h_{\mathrm{p}}$ of L0.12/0.8, more air-entraining was needed for L0.08/1.2 to get the reduced $h_{\mathrm{p}}$. In a word, the balance between volume fraction of steel fibers and airentraining controlled the water permeability of SFRELC.

When replacing lightweight sand by manufactured sand, the resistance of SFRELC to water penetration increased with the reduction of $h_{\mathrm{p}}$ from $10.2 \mathrm{~mm}$ to $8.1 \mathrm{~mm}$. This is due to the beneficial effects of stone powder in manufactured sand $[19,20]$ : the microaggregate filling effect on density, the activity effect and crystal nuclei effect on cement hydration degree, and the enhancement effect on hardness and bond property of the interfaces among the composites. Theoretically, these effects should also comprehensively improve the interfaces among steel fibers and set cement.

Given above, the mass loss rate reflected some information about the freeze-thaw resistance of SFRELC, where the negative and positive values gave the relative degree of water absorption and surface peeling off during the cycles of freezing and thawing. However, because of the integrity maintained and undetected surface scaling of SFRELC specimens, the mass loss rate was less changed with the increasing freeze-thaw cycles, and it was not a sensitive parameter to represent the freeze-thaw resistance of SFRELC.

3.2. Relative Dynamic Modulus of Elasticity. The dynamic modulus of elasticity is closely linked with the constitutes and microstructures of concrete, which is affected sensitively by the interior pores and unsubstantial interface [12, 33]. Figure 4 exhibits the changes of relative dynamic modulus of elasticity with freeze-thaw cycles affected by the content of

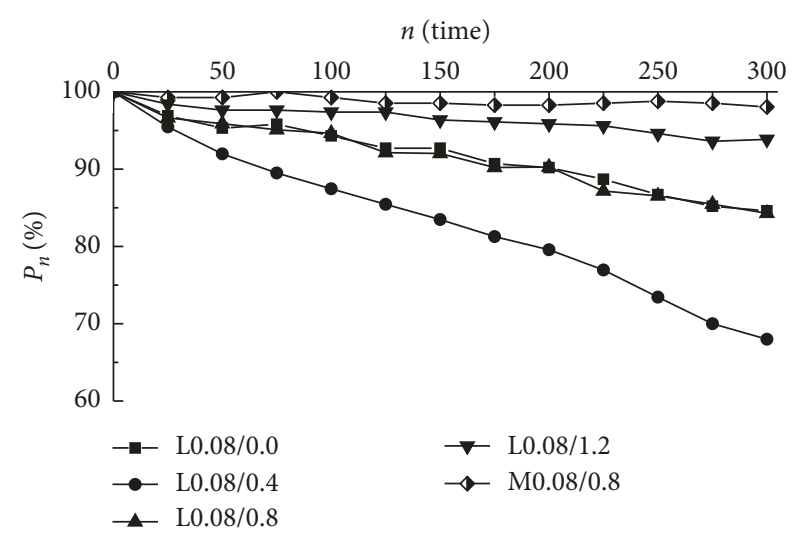

FIGURE 5: Changes of relative dynamic modulus affected by volume fraction of steel fibers and fine aggregates.

the air-entraining agent. Compared to L0.00/0.0, $P_{n}$ of L0.08/0.0 decreased slowly with the increasing freeze-thaw cycles. This is identical to the previous studies for the freezethaw resistance of lightweight aggregate concrete [9, 13-15], which benefits from the air-entraining effectiveness for the improvement of the microstructure with proper amount of closed and uniformly distributed microbubbles, resulting in the cutting-off of pores and capillaries inside concrete. At the same time, adding steel fibers in L0.00/0.8 without the airentraining agent led to the drop down of $P_{n}$. This is consistent with the increased depth of water penetration as shown in Figure 3. With the increasing content of the airentraining agent, the reduction of $P_{n}$ became slow, while the changes of $P_{n}$ for L0.08/0.8 and L0.08/0.0 were almost the same. When $m_{\mathrm{ae}}=0.12 \%$, the $P_{n}$ of L0.12/0.8 decreased slightly until $N=300$. Therefore, the $P_{n}$ of SFRELC was sensitive to the addition of steel fibers and the air-entraining agent. For the design of freeze-thaw resistance of SFRELC, the balance between the beneficial effect of the air-entraining agent and the harmful effect of steel fibers should be comprehensively considered.

Figure 5 exhibits the changes of relative dynamic modulus of SFRELC with freeze-thaw cycles affected by the volume fraction of steel fibers. With $m_{\mathrm{ae}}=0.08 \%$, the $P_{n}$ reduced slowly with the increasing volume fraction of steel fibers. When $\rho_{\mathrm{f}}=1.2 \%$, the $P_{n}$ reduced slightly. This exhibited that, with proper content of the air-entraining agent, SFRELC reached the higher freeze-thaw resistance with the assistance of a lager amount of steel fibers. Despite the increase of water penetration to some extent as shown in Figure 3, the beneficial effects of steel fibers on the confinement of internal shortages and the bridging on microcracks appeared successively $[6,11]$, and the integrity of SFRELC was maintained by overcoming the ice expansion in pores with the increasing freeze-thaw cycles. Therefore, the compound effect of the air-entraining agent and steel fibers led to the high freeze-thaw resistance of SFRELC.

Meanwhile, Figure 5 also exhibits the changes of relative dynamic modulus of SFRELC with freeze-thaw cycles affected by the fine aggregate. With $m_{\mathrm{ae}}=0.08 \%$ and $\rho_{\mathrm{f}}=0.8 \%$, the SFRELC with manufactured sand had higher 
TABLe 3: Test results of the DF of SFRELC.

\begin{tabular}{lccccccccc}
\hline Specimen no. & L0.00/0.0 & L0.00/0.8 & L0.04/0.8 & L0.08/0.4 & L0.08/0.0 & L0.08/0.8 & L0.12/0.8 & L0.08/1.2 & M0.08/0.8 \\
\hline$D F$ & 0.31 & 0.12 & 0.20 & 0.68 & 0.84 & 0.84 & 0.94 & 0.94 & 0.98 \\
\hline
\end{tabular}

TABle 4: Specified minimum value of the $D F$.

\begin{tabular}{|c|c|c|c|c|c|c|}
\hline \multirow{2}{*}{$\begin{array}{l}\text { Design service life } \\
\text { Environmental } \\
\text { condition }\end{array}$} & \multicolumn{2}{|c|}{100 years } & \multicolumn{2}{|c|}{50 years } & \multicolumn{2}{|c|}{30 years } \\
\hline & $\begin{array}{c}\text { Highly } \\
\text { saturated }\end{array}$ & $\begin{array}{c}\text { Moderately } \\
\text { saturated }\end{array}$ & $\begin{array}{c}\text { Highly } \\
\text { saturated }\end{array}$ & $\begin{array}{c}\text { Moderately } \\
\text { saturated }\end{array}$ & $\begin{array}{c}\text { Highly } \\
\text { saturated }\end{array}$ & $\begin{array}{c}\text { Moderately } \\
\text { saturated }\end{array}$ \\
\hline Severe cold area & 0.80 & 0.70 & 0.70 & 0.60 & 0.65 & 0.50 \\
\hline Cold area & 0.70 & 0.60 & 0.60 & 0.50 & 0.60 & 0.45 \\
\hline Partial freezing area & 0.60 & 0.60 & 0.50 & 0.45 & 0.50 & 0.40 \\
\hline
\end{tabular}

TABLE 5: Test results of the relative flexural strength of SFRELC.

\begin{tabular}{lccccc}
\hline \multirow{2}{*}{ Specimen no. } & \multicolumn{5}{c}{ Freeze-thaw cycles, $N$} \\
& 75 & 150 & 175 & 225 & 300 \\
\hline L0.00/0.0 & 46.5 & 18.9 & 9.8 & - & - \\
L0.00/0.8 & 62.7 & 29.7 & 17.4 & 3.4 & - \\
L0.04/0.8 & 71.6 & 41.6 & - & 19.6 & - \\
L0.08/0.0 & 95.3 & 83.8 & - & 75.3 & 63.4 \\
L0.08/0.4 & 77.5 & 53.0 & - & 41.8 & 26.2 \\
L0.08/0.8 & 96.6 & 89.0 & - & 82.3 & 74.1 \\
L0.12/0.8 & 95.2 & 86.9 & - & 82.1 & 74.9 \\
L0.08/1.2 & 96.1 & 89.3 & - & 85.7 & 80.0 \\
M0.08/0.8 & 95.3 & 94.9 & - & 88.4 & 81.9 \\
\hline
\end{tabular}

freeze-thaw resistance than that using lightweight sand. This is identical with the experimental results of water penetration shown in Figure 3.

Table 3 lists the test results of the DF of SFRELC. Table 4 presents the minimum value of the $D F$ specified in the Chinese standard for the durability design of concrete structures [7]. It can be seen that air-entraining is quite necessary for the SFRELC with certain freeze-thaw resistance even in the partial freezing area. With proper contents of the air-entraining agent and steel fibers, SFRELC with high freeze-thaw resistance can be applied in every freezing area, even in the highly saturated environmental condition of severe cold areas.

3.3. Relative Flexural Strength of SFRLAC. Table 5 lists the test results of the relative flexural strength of SFRELC with the increase of freeze-thaw cycles. The changes of relative flexural strength were similar to those of relative dynamic modulus of elasticity, which appeared more sensitive to the freeze-thaw cycles. Without adding the air-entraining agent, SFRELC lost the flexural strength rapidly after 75 freezethaw cycles. When $\rho_{\mathrm{f}}=0.8 \%$, the relative flexural strength of SFRELC obviously improved with the increase of $m_{\mathrm{ae}}$ from $0.04 \%$ o to $0.08 \%$. When $m_{\mathrm{ae}} \geq 0.08 \%$, SFRELC with $\rho_{\mathrm{f}} \geq 0.8 \%$ had higher relative flexural strength. Replacing lightweight sand with manufactured sand also gave the SFRELC with high relative flexural strength. These demonstrated that the flexural strength of SFRELC decreased with the increase of freeze-thaw cycles due to the weakened bond of steel fibers with the matrix.

\section{Conclusion}

In this paper, the effects of air-entraining, steel fibers, and fine aggregate type on the freeze-thaw resistance of SFRELC were experimentally studied and explained on the mechanisms in consistent with the test results of water penetration. The conclusions can be drawn as follows:

(1) Due to the water importing and exporting peculiarity of SFRELC, the mass loss rate could not reach the limit of $5 \%$. It was not a good index to evaluate the damage of SFRELC due to freezing and thawing. Comparatively, the relative dynamic modulus of elasticity of SFRELC had a clear trend to reflect the freeze-thaw resistance, and the relative flexural strength of SFRELC was more sensitive to the freezethaw cycles.

(2) Air-entraining was quite necessary for the development of SFRELC with high freeze-thaw resistance. Steel fibers were harmful to the freeze-thaw resistance of SFRELC without air-entraining. However, the harmful effect of steel fibers could be overcome with the assistance of air-entraining. With proper air-entraining, the freeze-thaw resistance of SFRELC increased with the increasing volume fraction of steel fibers. This exhibited the compound effect of the air-entraining agent and steel fibers on the freeze-thaw resistance of SFRELC.

(3) The replacement of lightweight sand with manufactured sand in SFRELC could enhance the freezethaw resistance. The reduction of relative dynamic modulus of elasticity became slow with the increasing freeze-thaw cycles, while the reduction of relative flexural strength became smaller.

(4) The proper mix proportion design should pay attention to the compound effect of the air-entraining agent and steel fibers, which controlled the degree of freeze-thaw resistance of SFRELC. In this experimental study, several instances of SFRELC with high freeze-thaw resistance were developed to meet the requirement of applying in freezing areas even in severe cold areas under highly saturated environmental condition; however, the quantitative relations for the design should be further studied. 


\section{Data Availability}

The data used to support the findings of this study are available from the corresponding author upon request.

\section{Conflicts of Interest}

The authors declare that they have no conflicts of interest.

\section{Acknowledgments}

This study was financially supported by the Special Project of State Research and Development Plan of Science and Technology (2017YFC0703904), the NCWU Innovation Funds for Doctoral Candidate (201714402), the Key Research Project in University of Henan Province, China (14B560004 and 16A560024), and the Science and Technology Innovation Team of Eco-Building Material and Structural Engineering in University of Henan Province, China (13IRTSTHN002).

\section{References}

[1] S. B. Zhao, C. Y. Li, and X. J. Qian, "Experimental study on mechanical properties of steel fiber reinforced full lightweight concrete," Geotechnical Special Publication, vol. 212, pp. 233-239, 2011.

[2] C. Y. Li, H. Chen, and S. B. Zhao, "Mechanical properties of steel fiber reinforced light-aggregate concrete," Advanced Materials Research, vol. 366, pp. 12-15, 2012.

[3] L. Y. Pan, H. Yuan, and S. B. Zhao, "Experimental study on mechanical properties of hybrid fiber reinforced full lightweight aggregate concrete," Advanced Materials Research, vol. 197-198, pp. 911-914, 2011.

[4] Z. Shen, M. H. Chen, M. S. Zhao, and X. K. Li, "Experimental study on tensile properties of steel fiber reinforced lightweight-aggregate fly-ash flowable concrete," in Architectural Engineering and New Materials, pp. 1-8, Destech Publications Inc., Lancaster, PA, USA, 2015.

[5] X. K. Li, X. Y. Zhang, M. Q. Li, M. S. Zhao, and C. Y. Li, "Experiments on development of strength and carbonization of steel fiber reinforced full-lightweight concrete," Journal of Civil Engineering and Management, vol. 34, no. 2, pp. 46-50, 2017.

[6] S. B. Zhao, C. Y. Li, M. S. Zhao, and X. Y. Zhang, "Experimental study on autogenous and drying shrinkage of steel fiber reinforced lightweight-aggregate concrete," Advances in Material Science and Engineering, vol. 2016, Article ID 2589383, 10 pages, 2016.

[7] GB/T 50476-2008, Code for Durability Design of Concrete Structures, China Building Industry Press, Beijing, China, 2008.

[8] H. Ishida, H. Iwase, K. Rokugou, and W. Koyanagi, "Improvement of freezing and thawing resistance of lightweight concrete by steel fiber addition," Transactions of the Japan Concrete Institute, vol. 7, pp. 135-140, 1985.

[9] J. Huo and X. Shen, "Experimental study on frost resistance durability of fiber reinforced lightweight aggregate concrete," Bulletin of the Chinese Ceramic Society, vol. 27, no. 5, pp. 952-956, 2008.

[10] J. Huo, D. Liu, X. Shen, J. Chu, and D. Dong, "Freeze-thaw model and service life prediction of hybrid fiber reinforced lightweight aggregate concrete," Advanced Materials Research, vol. 250-253, pp. 817-821, 2011.

[11] X. K. Li, W. H. Song, and C. Y. Li, "A review on frost resistance of steel fiber reinforced lightweight aggregate concrete," Applied Mechanics and Materials, vol. 438-439, pp. 295-299, 2013.

[12] C. Miu, High-performance Concrete Admixtures, Chemical Industry Press, Beijing, China, 2008.

[13] H. Li, X. Shen, and W. Kang, "Experiment on frost resistance durability of air-entrained pumice lightweight aggregate concrete," Concrete, vol. 6, pp. 73-76, 2009.

[14] Z. Y. Zhao, B. L. Ji, X. Y. Song, and X. D. Shen, "Frost resistance of lightweight aggregate concrete," Bulletin of the Chinese Ceramic Society, vol. 34, no. 9, pp. 2442-2447, 2015.

[15] W. A. Jones and W. W. Jason, "Freezing and thawing behavior of internally cured concrete," Advances in Civil Engineering Materials, vol. 4, no. 1, pp. 144-154, 2015.

[16] K.-S. Youm, J. Moon, J.-Y. Cho, and J. J. Kim, "Experimental study on strength and durability of lightweight aggregate concrete containing silica fume," Construction and Building Materials, vol. 114, pp. 517-527, 2016.

[17] JGJ 51-2002, Technical Specification for Lightweight Aggregate Concrete, China Building Industry Press, Beijing, China, 2002.

[18] GB/T 17431-2010, Lightweight Aggregate and Its Test Methods, China Standard Press, Beijing, China, 2010.

[19] X. X. Ding, C. Y. Li, Y. Y. Xu, F. L. Li, and S. B. Zhao, "Experimental study on long-term compressive strength of concrete with manufactured sand," Construction and Building Materials, vol. 108, pp. 67-73, 2016.

[20] S. B. Zhao, X. X. Ding, M. S. Zhao, C. Y. Li, and S. W. Pei, "Experimental study on tensile strength development of concrete with manufactured sand," Construction and Building Materials, vol. 138, pp. 247-253, 2017.

[21] JG/T 472-2015, Steel Fiber Reinforced Concrete, China Standard Press, Beijing, China, 2015.

[22] P. Zhao, Q. Bi, and Z. Yang, "Experimental study on the mechanical properties and durability of hybrid crude fiber reinforced lightweight aggregate concrete," Bulletin of the Chinese Ceramic Society, vol. 27, no. 4, pp. 852-856, 2008.

[23] M.-A. Ali, Y. Erhan, and A.-C. Özge, "Water transport of lightweight concrete with different saturation levels," $A C I$ Materials Journal, vol. 112, no. 5, pp. 681-691, 2015.

[24] J. Mao, K. Ayuta, H. Qi, and Z. Liu, "Experimental study on freeze-thaw damage mechanism of lightweight aggregate concrete," Journal of ASTM International, vol. 7, no. 1, pp. 1-12, 2010.

[25] B. Kucharczyková, Z. Keršner, O. Pospíchal, P. Misák, P. Daněk, and P. Schmid, "The porous aggregate pre-soaking in relation to the freeze-thaw resistance of lightweight aggregate concrete," Construction and Building Materials, vol. 30, pp. 761-766, 2012.

[26] L. Emiko, T. H. Wee, and T. Tamilselvan, "Penetrability of lightweight aggregate concrete," Magazine of Concrete Research, vol. 62, no. 3, pp. 201-209, 2010.

[27] K. S. Chia and M.-H. Zhang, "Water permeability and chloride penetrability of high-strength lightweight aggregate concrete," Cement and Concrete Research, vol. 32, pp. 639645, 2002.

[28] D. Sun, J. Ding, and Y. Guo, "Comparison of water permeability and chloride penetrability between normal-weight concrete and lightweight concrete made with different lightweight aggregates," Concrete, vol. 2, pp. 36-38, 2005.

[29] X. M. Liu, K. S. Chia, and M.-H. Zhang, "Development of lightweight aggregate concrete with high resistance to water 
and chloride-ion penetration," Cement \& Concrete Composites, vol. 32, pp. 757-766, 2010.

[30] GB/T 50082-2009, Standard for Test Method of Long-Term Performance and Durability of Ordinary Concrete, China Building Industry Press, Beijing, China, 2009.

[31] ASTM C666-97, Standard Test Method for Resistance of Concrete to Rapid Freeze and Thawing, ASTM International, West Conshohocken, PA, USA, 2008.

[32] GB/T 50081-2002, Standard for Test Method of Mechanical Properties of Ordinary Concrete, China Building Industry Press, Beijing, China, 2002.

[33] S. B. Zhao, Design Principle of Concrete Structures, Tongji University Press, Shanghai, China, 2nd edition, 2013. 


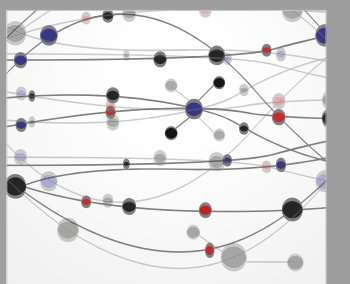

The Scientific World Journal
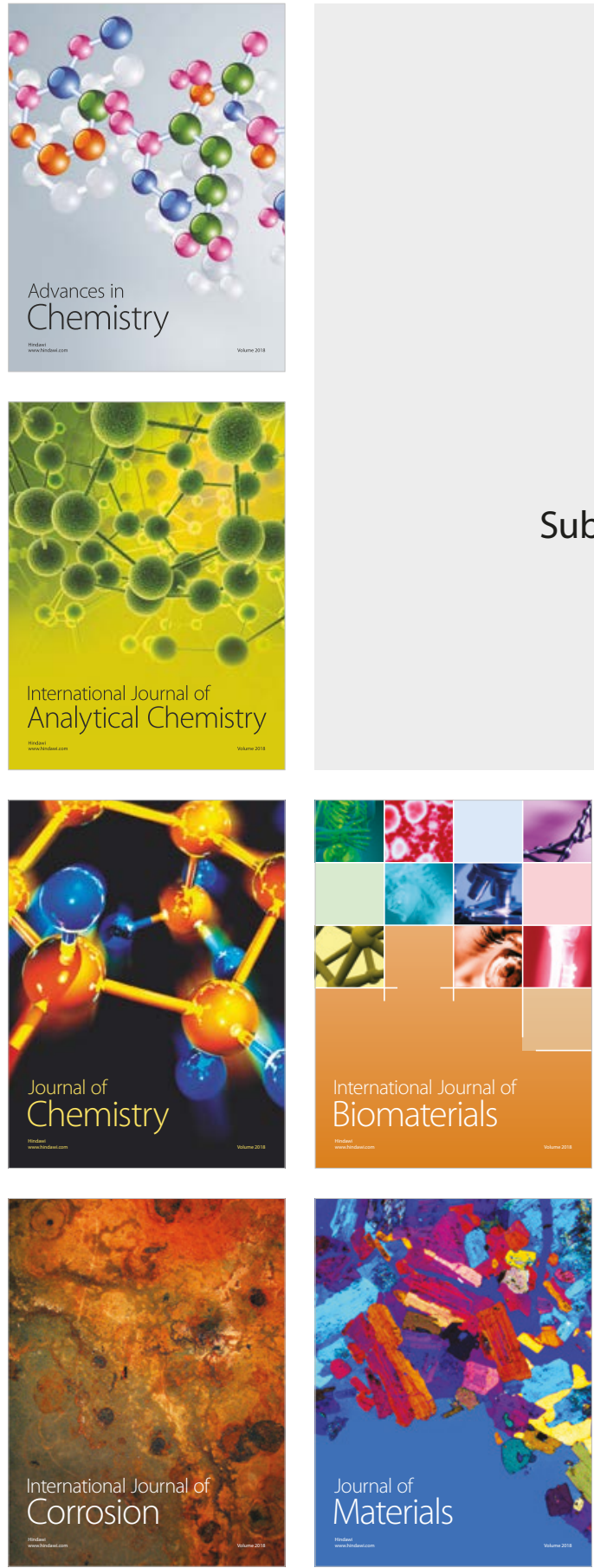

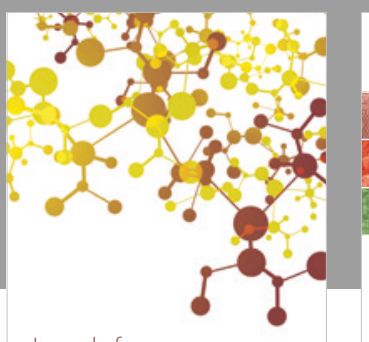

Journal of

Applied Chemistry
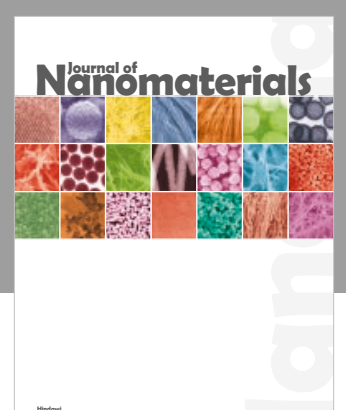

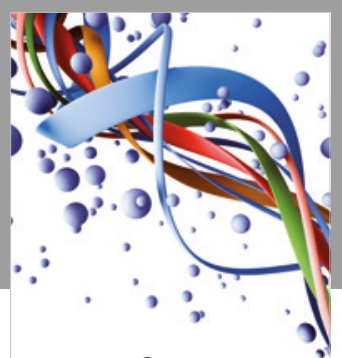

Scientifica

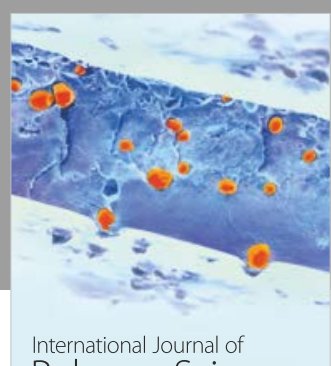

Polymer Science

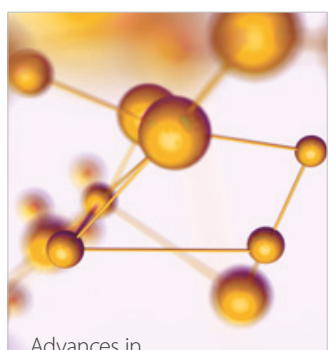

Physical Chemistry
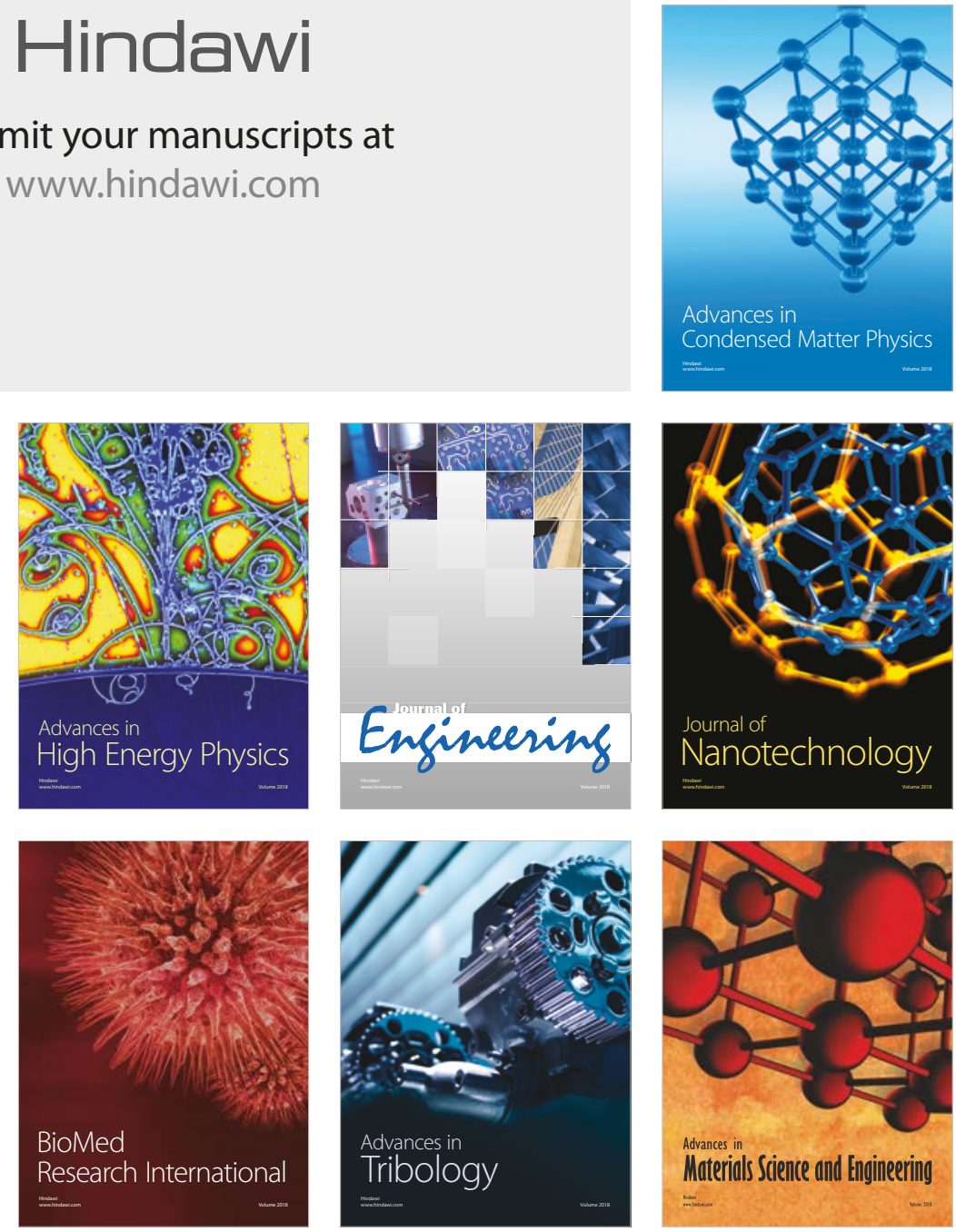